\title{
Study of physical and chemical properties of spray drying whey powder
}

\author{
Gholamreza Chegini • Ali HamidiSepehr • \\ Mohsen Fakher Dizaji · Seyed Vahid Mirnezami
}

Received: 17 April 2013/ Accepted: 4 May 2014/Published online: 22 May 2014

(C) The Author(s) 2014. This article is published with open access at Springerlink.com

\begin{abstract}
Background Making powder from whey is one of the most challenging parts of whey processing. The present study investigates the performance of a spray dryer for the preparation of whey powder. Its main objective is to categorize unknown samples using analysis of discrimination function between the operating variables and powder properties in two or more naturally occurring groups. In this work, spray drying was performed in a pilot-scale cocurrent spray dryer. The amount of solid content, inlet, and outlet air temperature was chosen as independent variables. The titratable acidity, PH, EC, TDS, analytical elements, particle size diameter, ingredients, and morphology were the response variables that quantify the powder quality.

Results The PH of whey powder with $15 \%$ solid content was lower than the PH of whey powder with $30 \%$ solid content. Furthermore, the $\mathrm{PH}$ of the whey dried at inlet (outlet) air temperature of $180{ }^{\circ} \mathrm{C}\left(106^{\circ} \mathrm{C}\right)$ was lower than the whey dried at $145^{\circ} \mathrm{C}\left(87^{\circ} \mathrm{C}\right)$. Substances with higher acidity had higher electrical conductivity (EC) as well. The mean particle diameters of the powders produced by pilotplant spray dryer were in the range of $11.26-18.23 \mu \mathrm{m}$. SEM picture showed that in pilot-plant spray dryer, there were a few shallow holes on the particle surfaces as well as a few wizened particles.

Conclusions It was observed that in the materials with higher acidity, the EC was high and the $\mathrm{PH}$ was low. More solid content caused higher viscosities in the feed, which increased the droplet size and consequently, the particle
\end{abstract}

G. Chegini $(\bowtie) \cdot$ A. HamidiSepehr · M. F. Dizaji ·

S. V. Mirnezami

Biosystem Engineering Department, College of Aboureihan,

University of Tehran, Tehran, Iran

e-mail: a.hamidisepehr@ut.ac.ir size. By increasing the temperature and heating duration, the amount of PH reduced and the diameter of the particles increased. Moreover, by increasing the percentage of the solid content, the PH increased, while the solid mass carried away by the outlet air decreased. Small particles sprayed by the two-fluid nozzles, led to less amount of TDS. From the morphological point of view, as the industrial samples were exposed to heat longer as compared to pilot-plant samples, they produced spherical and smoother particles.

Keywords Whey powder · Product quality - Spray drying

\section{Introduction}

Dairy products play an important role in human food. Hence, their quality is of significant concern for consumers, governmental control authorities, and manufacturers. One of the most nutrient dairy products is whey. Whey or milk serum contains a large amount of required body nutrition, including about $4.5 \%$ (weight over volume, or w/v) lactose, $0.8 \%$ $(\mathrm{w} / \mathrm{v})$ protein, $1 \%(\mathrm{w} / \mathrm{v})$ salt, and $0.1-0.8 \%(\mathrm{w} / \mathrm{v})$ lactic acid. Whey is transparent, yellowish-green and has a slight tart flavor (Grba et al. 2002). During the production of cheese, milk curdles and subsequently coagulates. Through this process, the hard part (casein) and the liquid part (whey) separate from each other, such that the liquid part includes nearly half of the milk solid ingredients (Keramat et al. 2007). In the process of producing one kilogram of cheese, about eight kilograms of whey are obtained. Although whey constitutes a considerable portion, since its nutrition facts are not well-known, it is wasted as wastewater (Estrella et al. 2004). Therefore, it must be the focus of more studies (Farkhondeh 1980). In fact, whey is significantly rich in terms of 
lactose, minerals, vitamins and protein (Glass and Hedrick 1976). The importance of lactase enzyme and introducing new sources of lactose is even more pronounced, when taken into consideration the large population suffering from lactose intolerance problem. Lactose intolerance, also called lactase deficiency and hypolactasia, is the inability to digest lactose, a sugar found in milk and to a lesser extent milkderived dairy products. Lactose intolerant individuals have insufficient levels of lactase, an enzyme that catalyzes hydrolysis of lactose into glucose and galactose, in their digestive system (NDDIC 2011).

Many products can be derived from whey through various processes and technologies. Among popular whey products are condensed whey, dried whey, modified dry whey, whey protein concentrate and isolates, as well as lactose (crystallized and dried). There are also many other secondary and tertiary products that can be derived from whey. Spray drying is a well-established method for converting liquid feed materials into dried powder form. Spray drying involves pumping a concentrated liquid feed through a device, which forms small droplets sprayed into hot air to dry rapidly and produce fine powdered products (Anandharamakrishnan et al. 2007; Masters 1991; Raffin et al. 2006). Four main processing steps are involved in spray drying: atomization, mixing of hot gas and atomized particles, droplets evaporation and collection of the dried products.

Each step is carried out considering the properties of the feed, dryer design and requisite quality of final product (Birchal et al. 2005). The variables in the main operating spray dryer are percentage of solid feed, inlet air temperature, and outlet air temperature. Outlet air temperature is the dominating factor in controlling the drying rate, which plays an important role in particle characteristic (Anandharamakrishnan et al. 2007, 2008). Each of the variables may have several effects on the drying process, which must be considered, carefully. As a result, an intelligent system is required for accurate automatic control of drying units, based on the specific process and product parameters. An automatic control is necessary for faster production, cost minimization, product quality consistency, and early warnings in case of problems (Chegini et al. 2008). On a different but related note, Chegini and Ghobadian (2005) also investigated the effects of inlet air temperature and some other test parameters, on spray-dried powder properties.

Market popularity of whey powder is directly influenced by its quality aspects. The operating spray dryer variables have greater effect on quality of whey powder. Moreover, several properties of whey powder, such as titratable acidity, PH, EC, TDS, analytical elements, particle size diameter, and morphology of particles, also depend on the operating variables. The main goal of the current work is to categorize some unknown samples, using discrimination function analysis between the operating variables and powder properties.

\section{Materials and methods}

Production of powder

Whey with solid content $(15,30$ and $40 \%)$ was provided from a local supplier and stirred and filtered for $30 \mathrm{~min}$. It was dried in a pilot-plant spray dryer, which had a diameter of $1.42 \mathrm{~m}$, cylindrical section height of $3.9 \mathrm{~m}$, and cone section height of $1 \mathrm{~m}$. The test equipment set-up is shown schematically in Fig. 1.

The air temperature and relative humidity were about $25-30{ }^{\circ} \mathrm{C}$, and $30-40 \%$, respectively. Whey feed (in $25-30{ }^{\circ} \mathrm{C}$ ) was pumped into the nozzle with a rate of $180 \mathrm{ml} / \mathrm{min}$, and $40 \mathrm{bar}$ pressure. Then, the atomization was performed by a twin-fluid nozzle, using compressed air at 1.5 bar. The atomizing gas was fed from an in-house supply. Two inlet air temperatures (Ti) of 180 and $145^{\circ} \mathrm{C}$ were used. The outlet air temperature (To) was monitored, continuously. Inlet and outlet air temperatures were read and manually logged directly from the digital displays on the dryer's control panel. To conduct the tests, six samples were selected. Each test was repeated three times (total of 18 tests). The parameters for each experiment are given in Table 1. After drying, powder samples were transferred into sealed bottles, to be maintained for the analysis step. To classify these samples, discrimination functions were used. Four industrial samples were chosen as unknown samples to discriminate their properties. Characteristics of industrial samples are shown in Table 2. These samples were studied for physical and chemical changes.

Some powder properties can be measured by analytical methods, as explained in the following section. These methods have been standardized in GEA Niro Method (2006).

Methods of property measurement

\section{Titratable acidity}

Titratable acidity is used to measure whey acidity ( $\mathrm{Li}$ and Shahbazi 2006). A sample of titratable hydrogen ions includes free insoluble $\mathrm{H}+$ ions and their combinations with acids and proteins. After being stored, the acidity of whey increased, which negatively influenced its flavor and acceptability. In other words, by staying in the storage, the acidity increased, the flavor worsened, and the acceptability decreased. The titratable acidity is determined by the titration of a known amount of reconstituted whey with 


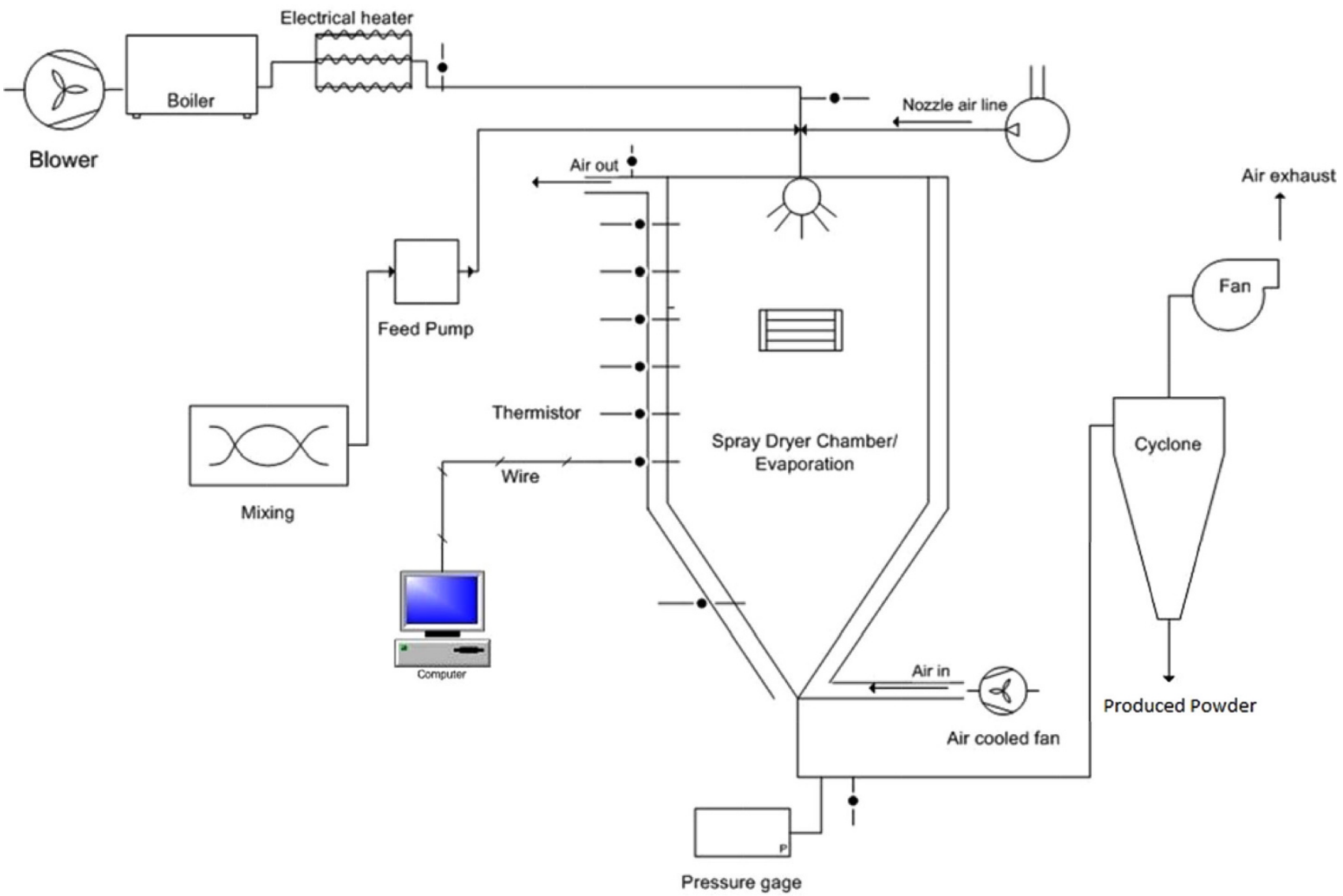

Fig. 1 Schematic view of test equipment

Table 1 The parameters of experimental design

\begin{tabular}{llll}
\hline $\begin{array}{l}\text { Samples } \\
\text { no. }\end{array}$ & $\begin{array}{l}\text { Nozzle } \\
\text { type }\end{array}$ & $\begin{array}{l}\text { Inlet/outlet air } \\
\text { temperature }\left({ }^{\circ} \mathrm{C}\right)\end{array}$ & $\begin{array}{l}\text { Solid content } \\
\%\end{array}$ \\
\hline 1 & Pressure & $180 / 106$ & 15 \\
2 & Pressure & $180 / 106$ & 30 \\
3 & Pressure & $145 / 87$ & 15 \\
4 & Pressure & $145 / 87$ & 30 \\
5 & Two-fluid & $180 / 106$ & 40 \\
6 & Two-fluid & $145 / 87$ & 40 \\
\hline
\end{tabular}

Table 2 Characteristics of industrial samples production

\begin{tabular}{ll}
\hline Inlet air temperature & $150-170{ }^{\circ} \mathrm{C}$ \\
Outlet air temperature & $80-90{ }^{\circ} \mathrm{C}$ \\
Solid content & $51-54 \%$ \\
Temperature of feed & $49-51{ }^{\circ} \mathrm{C}$ \\
Velocity of atomizer & $9,000-11,000 \mathrm{rpm}$ \\
Chamber's height & $7-9 \mathrm{~m}$ \\
\hline
\end{tabular}

$0.1 \mathrm{~N} \mathrm{NaOH}$ using phenolphthalein as the indicator. This method may be used for all types of dried milk products (ADMI Standard, GEA Niro Method No. A19a).
According to this standard, $6 \mathrm{~g}$ of whey powder was dispersed and dissolved in $100 \mathrm{ml}$ of deionised water, and stirred gently. Then, it was left for about $1 \mathrm{~h}$. Next, $20 \mathrm{ml}$ of this solution was poured into a $100 \mathrm{ml}$ Erlenmeyer flask and $0.5 \mathrm{ml}$ of phenolphthalein and titrate with $0.1 \mathrm{~N} \mathrm{NaOH}$ was added. It was left until a faint pink color persisted for $30 \mathrm{~s}$. The titratable acidity can be calculated using the following equation in which $v$ is volume of $0.1 \mathrm{ml} \mathrm{NaOH}, N$ is the normality of $0.1 \mathrm{ml}$ $\mathrm{NaOH}$, and $V$ is the volume of the milk solution in $\mathrm{ml}$.

$\%$ Titratable acidity $=\frac{v \times N \times 90 \times 100}{V \times 1000}$

\section{PH}

PH stands for "Potential Hydrogen", and refers to the amount of hydrogen mixed with water. PH is measured on a scale of $0-14$. The normal range for $\mathrm{PH}$ in ground water is between 6 and 8.5, while the milk PH is about 6.4. Some circumstances may lead to an increase in the $\mathrm{PH}$ values, by increasing the density of the concentrated liquid samples. If the heating temperature is greater than $100{ }^{\circ} \mathrm{C}$, lactose can be converted into a form of acid, especially formic acid, thereby decreasing the $\mathrm{PH}$. In this work, the $\mathrm{PH}$ of each sample was determined using a digital $\mathrm{PH}$ meter at $25^{\circ} \mathrm{C}$. 


\section{$E C$ and TDS}

The conductivity of a particular material with respect to electrical current is called electrical conductivity (EC), and expressed in units of Micro Siemens to centimeter. The EC measurement might be the most popular test to determine material properties. The expression "Total Dissolved Solids" (TDS) refers to the total amount of all inorganic and organic substances (including minerals, salts, metals, cations or anions) that are dissolved in a volume of water. Amounts of TDS are used to evaluate the quality of solutions. Value of TDS is equal to the sum of positively charged ions (cations) and negatively charged ions (anions) in the water. The EC and TDS of each sample were determined using a digital conductivity meter at $25^{\circ} \mathrm{C}$.

\section{Analytical elements and particle diameter}

A Philips XL-30 model (The Netherlands) scanning electron microscope was used to measure the diameter of particles produced by the spray dryer. This system was equipped with an energy dispersive spectrometer (also known as energy dispersive X-ray (EDX) microanalysis) that was used to investigate the analytical elements and ingredients.

\section{Morphology of whey powder particles}

Morphology of powder particles indicates their physical construction. Physical construction is related to the shape of a particle, as well as its placement with respect to other particles. The spherical shape may change, due to a structural change or breaking of the particles. The particles may either be sticking together or separated from each other. These elements generally affect the powder properties.

\section{Classification analysis}

Discrimination function analysis is used to distinguish the continuous variables between two or more naturally occurring groups. Classification analysis technique can help us to assign multivariate data into distinct groups. For each sample, the values of the functions for various groups are determined, and the sample will be assigned to the group that gives the largest function value. Once the discrimination functions are derived, groups are classified. The quality of these functions can be determined by examining their ability to classify samples whose classes are already known. In this work, the classification functions were derived from the linear discrimination functions. The classification functions can be used to assign each case to the most likely group.

\section{Results and discussion}

Physical and chemical analyses of whey powder produced by pilot-plant and industrial-plant spray dryer for 10 samples are shown in Tables 3 and 4, respectively. The PH of whey powder with $15 \%$ solid content was lower than the PH of whey powder with $30 \%$ solid content. Furthermore, the $\mathrm{PH}$ of whey dried at inlet (outlet) air temperature of $180{ }^{\circ} \mathrm{C}\left(106{ }^{\circ} \mathrm{C}\right)$ was lower than the whey dried at $145^{\circ} \mathrm{C}$ $\left(87^{\circ} \mathrm{C}\right)$. Some circumstances led to an increase in the density of the concentrated liquid samples, which resulted in an increase in the $\mathrm{PH}$ values. Moreover, samples with higher $\mathrm{PH}$ values have lower EC.

The lactose in dairy, when exposed to appropriate temperature and in presence of some microbes, converted into lactic acid and subsequently tended to be more acidic. Therefore, in the results shown in Tables 3 and 4, the acidity was calculated based on the lactic acid. Usually, substances with higher acidity have higher EC as well. However, in some cases, it is not true because of the particular aggregation of powder particles and the number of powder particles in the dissolved whey.

Tables 3 and 4 show that acidity for industrial samples was more than acidity for pilot-plant samples. It was caused by the temperature conditions in industrial dryer. Considering the volume of spray dryer and its capacity, heating time for particles was too long, which caused more

Table 3 Typical physical and chemical analyses of whey powder produced by pilot-plant spray dryer

\begin{tabular}{lrllll}
\hline $\begin{array}{l}\text { Sample } \\
\text { no. }\end{array}$ & Acidity & PH & $\begin{array}{l}\text { EC } \\
\left(\mathrm{cm}^{3} / \mathrm{cm}\right)\end{array}$ & $\begin{array}{l}\text { TDS } \\
(\mathrm{mg} / \mathrm{l})\end{array}$ & $\begin{array}{l}\text { Mean D } \\
(\mu \mathrm{m})\end{array}$ \\
\hline 1 & 45.04 & 6.705 & 6.004 & 177 & 35.78 \\
& 45.04 & 6.698 & 6.008 & 178 & 35.71 \\
& 54.048 & 6.706 & 5.998 & 177 & 35.80 \\
2 & 81.072 & 6.577 & 6.312 & 187 & 38.23 \\
& 72.064 & 6.581 & 6.316 & 188 & 38.17 \\
& 72.064 & 6.574 & 6.310 & 189 & 38.23 \\
3 & 49.544 & 6.733 & 6.194 & 183 & 31.07 \\
& 54.048 & 6.730 & 6.190 & 182 & 31.12 \\
& 54.048 & 6.733 & 6.189 & 185 & 31.01 \\
4 & 45.04 & 6.612 & 5.902 & 174 & 33.35 \\
& 54.048 & 6.613 & 5.496 & 174 & 33.34 \\
& 54.048 & 6.608 & 5.908 & 176 & 33.25 \\
5 & 63.056 & 7.031 & 4.846 & 140.5 & 34.44 \\
& 72.064 & 7.029 & 4.849 & 142 & 34.54 \\
& 63.056 & 7.034 & 4.846 & 139 & 34.51 \\
& 54.048 & 7.162 & 5.354 & 156.5 & 31.30 \\
& 54.048 & 7.164 & 5.360 & 155 & 31.26 \\
& 45.04 & 7.164 & 5.350 & 157 & 31.37 \\
\hline
\end{tabular}


Table 4 Typical physical and chemical analyses of whey powder produced by industrial-plant spray dryer

\begin{tabular}{lcllll}
\hline $\begin{array}{l}\text { Sample } \\
\text { no. }\end{array}$ & Acidity & PH & $\begin{array}{l}\text { EC } \\
\left(\mathrm{cm}^{3} / \mathrm{cm}\right)\end{array}$ & $\begin{array}{l}\text { TDS } \\
(\mathrm{mg} / \mathrm{l})\end{array}$ & $\begin{array}{l}\text { Mean D } \\
(\mu \mathrm{m})\end{array}$ \\
\hline 7 & 101.34 & 6.705 & 6.004 & 177 & 15.78 \\
8 & 74.316 & 6.577 & 6.312 & 187 & 18.23 \\
9 & 110.35 & 6.733 & 6.194 & 183 & 11.07 \\
10 & 78.82 & 6.612 & 5.902 & 174 & 13.35 \\
\hline
\end{tabular}

conversion of lactose into lactic acid. Accordingly, EC in industrial samples was more and $\mathrm{PH}$ level was lower.

As mentioned earlier, TDS are considered as an index to determine the quality of liquids. According to the results obtained from the experiment, the TDS of powder samples 5 and 6 were significantly lower than that of other samples. In fact, spray dryers with two-fluid nozzles produced smaller grains as compared to the pressure nozzles. Hence, at the end of the drying process, separator cyclone released a large amount of powder together with the outlet. Small particles can lead to lower amount of TDS.

The results in Tables 3 and 4 also show that the TDS for industrial samples were more than the TDS for pilot-plant samples. This observation is justified by pointing out that particles in industrial samples had larger aggregation. According to the definition, larger particles have higher TDS.

Average size of whey powder particles produced for ten samples is given in Table 3. The mean particle diameters (Mean D) of all the powders produced by pilot-plant spray dryer were in the range of $11.26-18.23 \mu \mathrm{m}$. It can be observed that by increasing the inlet (outlet) air temperature, the diameter of the particles increased. By increasing the inlet air temperature, the top surface dried quickly. This hard layer did not allow internal moisture to leave the particle and led it to inflation, which increased the particle size. Comparing pilot-plant with industrial samples, it can be inferred that although industrial samples are more homogenous, they are similar to each other regarding particle size. Inlet (outlet) air temperature above water boiling point leads to water boiling in the drops; consequently, particles are inflamed and diameter of the particles increases. In addition, by decreasing solid content, particles would have thinner shell which causes faster evaporation. Thus, particles take a wrinkled form with smaller diameter.

Higher feed solid content caused a decrease in the solid mass carried away by the exhausted air due to its effect on the particle size. Also Goula and Adamopoulos (2004) perceived that higher feed solid contents lead to higher feed viscosity, increase in droplet diameter and, therefore, increase in the particles size.

The electrical conductivity is mainly related to whey ingredients, especially sodium, potassium and chlorine

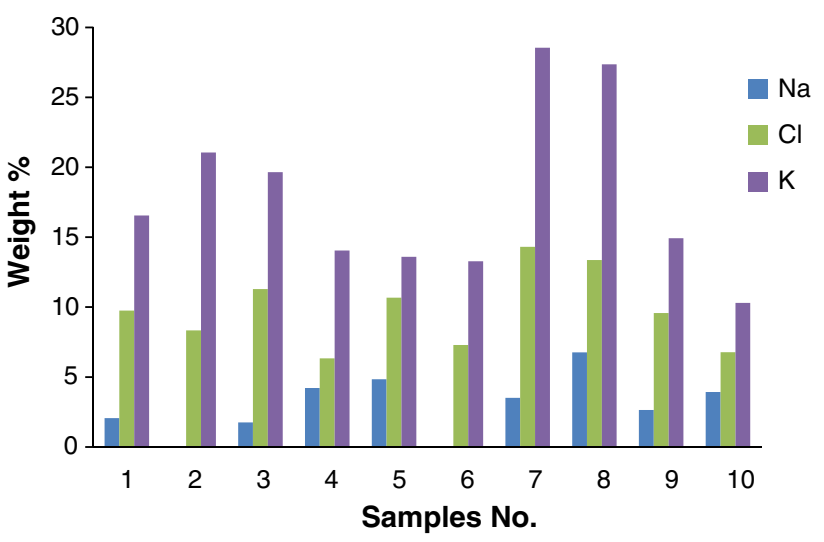

Fig. 2 Analytical elements of whey powder

ions. Increasing the concentration of these ions also increases the EC. Samples 2 and 3 among the pilot-plant samples and 7 and 8 among the industrial-plant samples had the greatest amount of these ions, which confirmed the results of the measured EC. Amounts of different ions in the samples are shown in Fig. 2.

To verify the morphology of whey powder particles, a pilot-plant sample and an industrial-plant sample at the same condition were studied and evaluated. SEM picture of the pilot-plant sample with magnification of 100 times is shown in Fig. 3a. As can be seen in the picture, this sample was a mixture of broken particles and smooth particles with spherical shape. Moreover, some small holes appeared on the surface of a few particles. Figure $3 \mathrm{~b}$ shows that in some cases, there were a few shallow holes on the particle surfaces as well as a few wizened particles. This picture has a magnification of 500 times. Smooth and broken particles are indications of a fragile powder. After spraying, due to the high dryer temperature (inlet temperature $180{ }^{\circ} \mathrm{C}$ and outlet temperature $106^{\circ} \mathrm{C}$ ), the outer surface of the droplet dried quickly and this hard layer prevented moisture to leave the droplet. But considering that the chamber air temperature was above the water boiling point, the trapped moisture in the outer dried layer vaporized. This layer allowed water, vapor and unsolved gases to move from internal layers to the particle surface with minimal resistance. Therefore, a minimum pressure from inside caused the shell of the particle to destroy or perforate.

SEM picture of the industrial-plant sample is shown in Fig. 4, with magnification of 500 times. Because of the larger volume and the height of the industrial spray dryer chamber, particles were exposed to heat for a longer time, compared to pilot-plant, which let production of spherical and smoother particles. Meanwhile, hunk state was observed in the figure, too. 

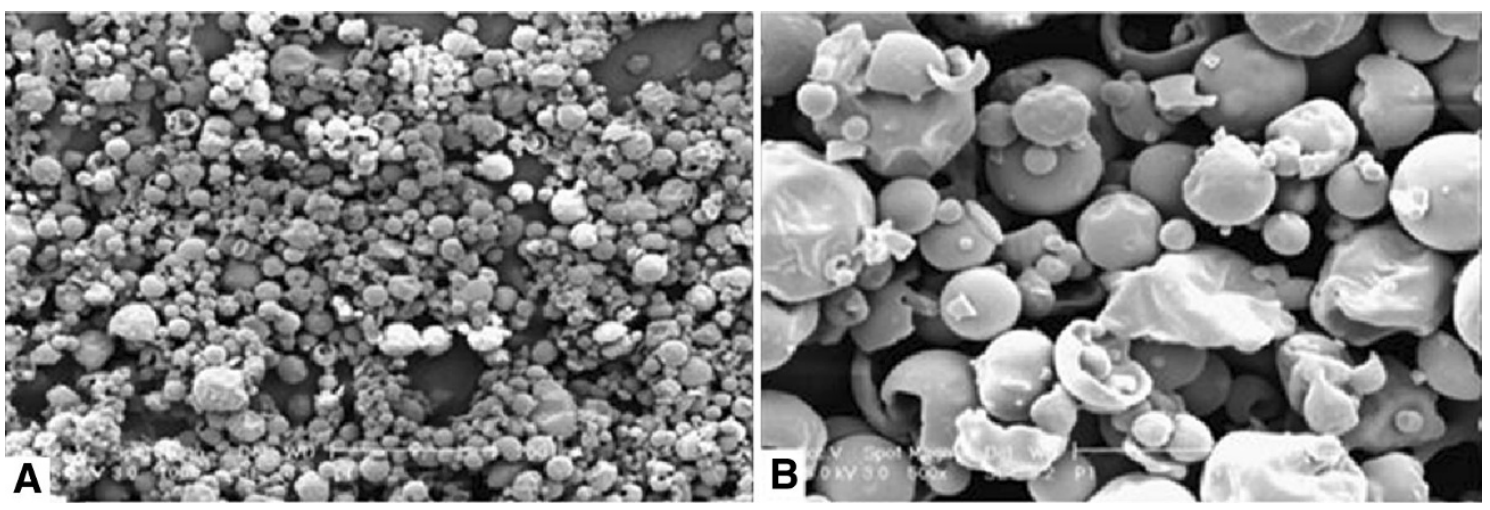

Fig. 3 SEM picture for produced powder in pilot-plan spray dryer with magnification of $\mathbf{a} \times 100$ and $\mathbf{b} \times 500$

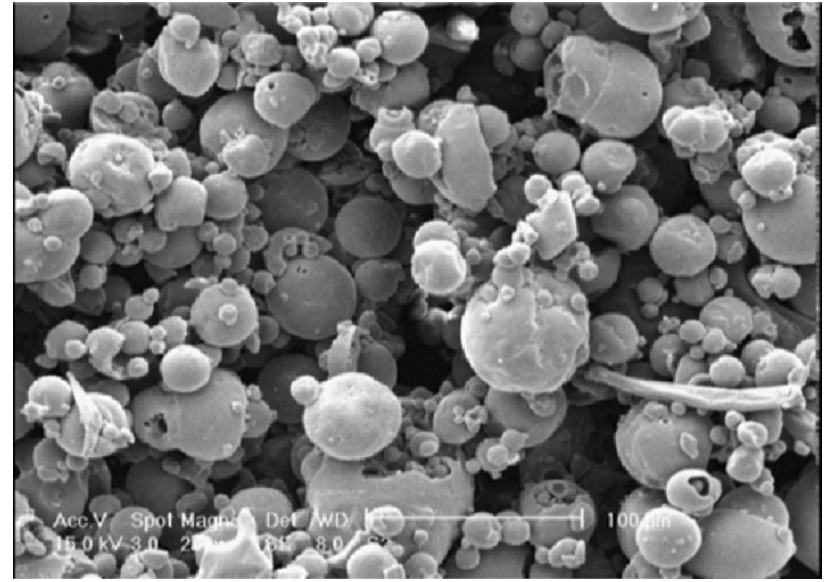

Fig. 4 SEM picture for produced powder in an industrial-plan spray dryer

\section{Conclusions}

The results of a study on physical and chemical properties of spray drying whey powder were presented in the current study. The main objective was to be able to categorize unclassified samples, after developing the discrimination functions, based on the operating variables and powder properties. Physical and chemical properties were used in the lab for quality control and analysis. In dairy productions, lactose transforms into lactic acid in appropriate temperature and in presence of some microbes. It enabled us to measure the acidity, based on the lactic acid. Usually, substances with higher acidity have higher EC as well. However, in some cases, it may not be true, because of the particular aggregation of powder particles and the number of powder particles in the dissolved whey. By increasing the temperature and duration of heating, the amount of $\mathrm{PH}$ reduced and the diameter of the particles increased. Moreover, by increasing the percentage of the solid content, the PH increased while the solid mass carried away by the outlet air decreased. Spray dryers with twofluid nozzles produced smaller grains as compared to the pressure nozzles. Small particles sprayed by the two-fluid nozzles led to less amount of TDS. From the morphological point of view, as the industrial samples were exposed to heat longer, compared to pilot-plant samples, they produced spherical and smoother particles.

Acknowledgments We wish to thank Department of Agro Technical, College of Aboureihan, University of Tehran, Tehran, Iran.

Open Access This article is distributed under the terms of the Creative Commons Attribution License which permits any use, distribution, and reproduction in any medium, provided the original author(s) and the source are credited.

\section{References}

Anandharamakrishnan C, Rielly CD, Stapley AGF (2007) Effects of process variables on the denaturation of whey proteins during spray drying. J Dry Technol 25(5):799-807

Anandharamakrishnan C, Rielly CD, Stapley AGF (2008) Loss of solubility of $\alpha$-lactalbumin and $\beta$-lactoglobulin during the spray drying of whey proteins. J LWT 41:270-277

Birchal VS, Passos ML, Wildhagen GRS, Mujumdar AS (2005) Effect of spray dryer operating variables on the whole milk powder quality. J Dry Technol 23:611-636

Chegini GR, Ghobadian B (2005) Effect of spray drying condition on physical properties of orange juice powder. J Dry Technol 23(3):657-668

Chegini GR, Khazaei J, Ghobadian B, Goudarzi AM (2008) Prediction of process and product parameters in an orange juice spray dryer using artificial neural networks. J Food Eng 84:534-543

Estrella MJ, Pieckenstain FL, Marina M, Diaz LE, Ruiz OA (2004) Cheese whey: an alternative growth and protective medium for Rhizobium loti cells. J Ind Microbiol Biotechnol 31:122-126

Farkhondeh A (1980) Milk and its products in human nutrition. Mihan, Tehran, Iran, p 96

Glass L, Hedrick TI (1976) Nutritional composition of sweet and acid type dry whey. J Dairy Sci 60(2):185-189

Goula AM, Adamopoulos KG (2004) Spray drying of tomato pulp: effect of feed concentration. J Dry Technol 22(10):2309-2330 
Grba S, Stehlik-Tomas V, Stanzer D, Vahcic N, Skrlin A (2002) Selection of yeast strain Kluyveromyces marxianus for alcohol and biomass production on whey. Chem Biochem Eng Q 16(1):13-16

Keramat J, Dokhani S, Bozorgzad M (2007) A study of the effects of whey concentrate and whey powder, on the quality of wheat flour-baked products. Iran J Agric Sci 37(6):1067-1081

Li Y, Shahbazi A (2006) Lactic acid recovery from cheese whey fermentation broth using combined ultrafiltration and nanofiltration membranes. Appl Biochem Biotechnol 132(1-3):985-996
Masters K (1991) Spray drying handbook. Longman Scientific and Technical, Harlow

National digestive diseases information clearinghouse (NDDIC) NIDDK Retrieved 29 November 2011. http://digestive.niddk. nih.gov/ddiseases/pubs/lactoseintolerance/. Accessed 9 Feb 2013

GEA Niro (2006) http://www.niro.com/niro/cmsdoc.nsf/webdocprint. Accessed 8 Oct 2008

Raffin RP, Guterres SS, Pohlmann AR, Ré MI (2006) Powder characteristics of pantoprazole delivery systems produced in different spray dryer scales. J Dry Technol 24(3):339-348 